\title{
Can International Crude Oil Futures Stabilize the Crude Oil Spot Price Fluctuations in China?
}

\section{-An Empirical Study Based on VEC - BEKK - GARCH $(1,1)$ Model}

\author{
Yan $\mathrm{Ge}^{1}$ Haixia $\mathrm{Wu}^{2}$
}

\author{
${ }^{1}$ Finance and Taxation Institute, Central University of Finance and Economics, Beijing, 100081 \\ ${ }^{2}$ Shaanxi Normal University, International Business School, Xi'an, Shaanxi, 710119
}

\section{Keywords: Crude Oil Futures; Crude Oil Spot; Spillover Effect; Cointegration Analysis}

\begin{abstract}
Based on the international crude oil futures price and the spot price of crude oil in China from January 4, 2006 to August 20, 2014, the VEC-BEKK-GARCH (1, 1) model was used to analyze the international crude oil futures prices and the crude oil Fluctuation relationship between spot prices. (1) There is a two-way causal relationship between the international crude oil futures price and the fluctuation of the spot price of crude oil in China. (2) The cointegration coefficient between the international crude oil futures price and the spot price of crude oil in China is (1, -1.0928) (3) At the same time, the international crude oil futures prices show a significant price on Chinese crude oil spot price guide function, but the contrary is not established. (3) At the same time, the international crude oil futures prices show a significant price of Chinese crude oil spot price guide function, but the contrary is not established.
\end{abstract}

\section{Introduction}

Crude oil is not only an important chemical raw material, but also an indispensable basic industrial product for the development of the national economy. Every prosperity and depression in the world economy are inextricably linked with the fluctuation of oil prices, especially for the developing countries. According to the World Bank 2014 World Economic Development Report, crude oil prices are closely related to economic development and have become an important factor affecting national economic development, social stability and national defense. In the case of developing countries, the price of crude oil per barrel continued to rise by $\$ 10$ a year, and its average annual economic growth rate would be reduced by 0.75 percentage points. With the expansion of the scope and level of crude oil price fluctuations, the economic attributes of crude oil gradually weakened, financial and political attributes highlight the world to grasp the control of crude oil prices.

The study of crude oil price volatility has also been the focus of attention in academia. On the one hand, fluctuations in crude oil prices make crude oil producers and consumers into a great deal of uncertainty and have an impact on investors' investment behavior. From the short-term energy output ratio, crude oil price volatility makes the producers adjust the capital and labor investment to meet the cost of minimizing the demand, and capital and labor conversion costs will reduce the production efficiency; in the long run, crude oil prices of the changes in the relative price of inputs, resulting in reallocation of resources between industries and sectors, resulting in increased allocation costs that will slow down the growth rate of output and cause a recession. Crude oil in the economic and social countries in the important position makes the stability of crude oil prices become the core issue of the world's macro management. The futures market is the price of crude oil in any country when the price of crude oil futures is improved, and the price of crude oil futures is becoming more and more obvious Need to be considered carefully.

From the history of the futures market can be seen, the original intention of the futures market is to hedge spot prices, stable spot market. With the continuous development and deepening of the futures market, its financial attributes and high risk increasingly prominent, making the futures market is not entirely play a risk aversion effect, in fact, may enlarge the spot market price fluctuations, so the futures market is flat Spot price fluctuations or play a role in amplification, practitioners and academia there is no uniform conclusion, and there is a big difference. Some of the 
futures market participants and scholars from the empirical point of view that the futures market does play a stable spot market price fluctuation, but the performance of the futures market, the other part of the scholars and futures markets of the participants hold the opposite view. Such as Chinese Zhengzhou Commodity Exchange launched mung bean futures contracts, due to excessive speculation investors, futures prices did not really reflect the spot market price fluctuations, but there has been a serious separation of the current, the government implemented a mandatory administrative intervention, The spot market prices are still volatile, and the emergence of a five-year period is completely separated from the phenomenon.

At present, Chinese crude oil dependence on up to $60 \%$, but so far, China has not introduced a complete crude oil futures contracts in the crude oil market subject to fluctuations in the international market, there is no basic pricing and voice, Chinese economy thus bear a greater risk. Therefore, in this context, this article will be based on the January 4, $2006 \sim$ August 20, 2014 international crude oil futures and Chinese crude oil spot price data, the use of VEC-BEKK-GARCH model in-depth study of international crude oil futures prices and The relationship between the spot price of crude oil in China, in order to analyze the actual data of the two, obtain the quantitative relationship between the change and the mutual influence, and lay a solid theoretical foundation for the construction of Chinese crude oil futures market and the introduction of futures contracts.

\section{The Literature Review}

Financial theory that if the futures market is efficient, the futures market and the spot market response to the same information should be basically similar to the impact. But the theoretical study, the futures market on the spot market is to stabilize or enlarge the price fluctuations are still quite different. The introduction of futures contracts will help stabilize spot prices. However, some scholars have different views on this, such as Cox (1976), Stein (1987) and so that low buy and sell is not the best strategy for investors, investors trading depends on its future price of goods expected, due to Rational expectations exist, and investors' trading behavior may amplify price volatility. For example, Zhong et al. (2004) used the EGARCH model to study the impact of Mexican stock index futures on spot price volatility and found that the futures market did not stabilize and dominate the spot market. On the contrary, the emergence of stock index futures exacerbated the spot market the volatility.

In the actual study, the academic market on the futures market price of the spot market to stabilize or enlarge the role is still divided. (Schwarz \& Szakmary, 1994; Foster, 1996; Silvapulle \& Moosa, 1999; Moosa, 2002) first explored the discovery of the spot price on crude oil futures prices. Quan (1992) used the Garbade-Silber Model and monthly data to measure the price discovery function of the crude oil futures market. The results showed that the crude oil futures market did not play a function of price discovery for a long time. People tend to think that crude oil futures On the spot with the price discovery function and pricing efficiency is due to the introduction of futures contracts, crude oil spot prices are often able to quickly aggregate. Schwarz \& Szakmary (1994) argues that Schwarz \& Szakmary (1994) argues that Quan (1992) uses monthly data to reflect the price lead in the crude oil futures market, as the crude oil market price reacts more rapidly Function, Schwarz \& Szakmary (1994) based on the data found that crude oil futures prices on the spot price has a strong pricing efficiency and price lead function. The two methods have different conclusions about the existence of Granger causality between crude oil futures and crude oil spot market.

The above literature can be seen, the existing literature on the futures market is stable to the spot market price volatility is inconclusive, and the relationship between the two studies focused on cointegration, linear and non-linear relationship and the price between the two Guidance and pricing efficiency of the study, the above discussion for the idea of this article provides inspiration, laid the foundation, but the existing research there is still room for further improvement: (1) Europe and the United States and other countries more perfect crude oil futures market makes the existing research focused on the same Country or the same species of crude oil futures and spot relationship between 
the two transnational or cross-market transfer effect of the lack of research. (2) In terms of crude oil market, since China has not yet launched a crude oil futures market, it is difficult to directly study the price discovery and pricing efficiency of Chinese crude oil futures market and spot market. Chinese annual crude oil consumption import gap is large, but so far has not yet launched crude oil futures contracts, the transfer effect of the two studies on Chinese crude oil futures market and the introduction of futures contracts have important policy implications. Based on the daily data of international crude oil futures and the spot price of crude oil in China, the VEC-BEKK-GARCH $(1,1)$ model system is used to analyze the international crude oil futures market. Chinese crude oil spot market impact, so as to the introduction of crude oil futures contracts to lay a solid theoretical foundation.

\section{The Mathematical Model and Data Description}

Vector Error Correction Model. For non-stationary time series modeling with cointegration relations, a vector error correction model is used (Gao et al., 2009). Cointegration and VEC model correspondence, making the time series will not deviate from the long-term equilibrium, both short-term dynamic adjustment and long-term equilibrium process. However, based on the causal relationship between the VEC model cannot examine the second-order moments of market volatility, can only be used to examine the relationship between the price changes between the two markets. If there is an ARCH effect on the residual of the VEC model, it indicates that there is a time variance in the residual term. Therefore, this paper will introduce the binary BEKK-GARCH model, a comprehensive look at the international crude oil futures prices on Chinese crude oil spot price impact and spillover effect. In the specific model design, we first set the following vector error correction model:

$$
\begin{gathered}
\Delta c p_{t}=\mu_{c}+\alpha_{1} E C M_{t-1}+\sum_{i=1}^{m} \beta_{1 i} \Delta f p_{t-i}+\sum_{i=1}^{m} \gamma_{1 i} \Delta \mathrm{cp}_{t-i}+\varepsilon_{1 t} \\
\Delta f p_{t}=\mu_{f}+\alpha_{f} E C M_{t-1}+\sum_{i=1}^{m} \beta_{2 i} \Delta f_{t-i}+\sum_{i=1}^{m} \gamma_{2 i} \Delta c_{t-i}+\varepsilon_{2 t}
\end{gathered}
$$

VEC-BEKK-GARCH Model. The VEC model provides the results of the co-integration between the international crude oil futures price and the spot price of crude oil in China. The BEKK model proposed by Engle and Kroner (1995) is used to analyze the relationship between the international crude oil futures price and the spot price of crude oil. The specific VEC- The BEKK-GARCH model is set to:

$$
H_{t}=C^{\prime} C+B^{\prime} H_{t-1} B+A^{\prime}\left(\varepsilon_{t-1} \varepsilon_{t-1}^{\prime}\right) A
$$

The matrix form is:

$$
\begin{gathered}
\left(\begin{array}{l}
h_{11, t} h_{12, t} \\
h_{21, t} h_{22, t}
\end{array}\right)=\left(\begin{array}{ll}
c_{11} & c_{12} \\
0 & c_{22}
\end{array}\right)^{\prime}\left(\begin{array}{ll}
c_{11} & c_{12} \\
0 & c_{22}
\end{array}\right)+\left(\begin{array}{l}
b_{11} b_{12} \\
b_{21} b_{22}
\end{array}\right)^{\prime}\left(\begin{array}{l}
h_{11, t-1} h_{12, t-1} \\
h_{21, t-1} h_{22, t-1}
\end{array}\right)\left(\begin{array}{l}
b_{11} b_{12} \\
b_{21} b_{22}
\end{array}\right) \\
+\left(\begin{array}{l}
a_{11} a_{12} \\
a_{21} a_{22}
\end{array}\right)^{\prime}\left(\begin{array}{ll}
\varepsilon_{1, t-1}{ }^{2} & \varepsilon_{1, t-1} \varepsilon_{2, t-1} \\
\varepsilon_{2, t-1} \varepsilon_{1, t-1} & \varepsilon_{2, t-1}^{2}
\end{array}\right)\left(\begin{array}{l}
a_{11} a_{12} \\
a_{21} a_{22}
\end{array}\right)
\end{gathered}
$$

Data Description. The data used in this paper are from the Wende database, respectively, from January 4, 2006 to August 20, 2014 international crude oil futures prices (US dollars / barrel) and Chinese crude oil spot price (US dollars / barrel) of the daily data The As a result of the differences in domestic and foreign holidays, some of the statistical data is missing, this paper will not completely overlap the two markets to delete data (Hamao et al., 1990), get 2216 sample data.

During the sample period, the international crude oil futures prices and Chinese crude oil spot price trend is basically the same, the two have a strong correlation. From January 2006 to January 2007, the international crude oil futures prices and Chinese crude oil spot price fluctuations, the price hovering low; February 2007 August 2008, the international crude oil futures prices and 
Chinese crude oil spot prices rose sharply, Respectively, from \$ 52.18 / barrel and \$ 45.30 / barrel climbed to \$ 145.68 / barrel and \$ 135.86 / barrel, an increase of $179.19 \%$ and 199.91\%. Subsequently, the international crude oil futures prices and Chinese crude oil spot prices quickly fell to the end of 2008 the price bottom, respectively fell to 35.98 US dollars / barrel and 33.05 US dollars / barrel. Since the beginning of 2009, the international crude oil futures prices and Chinese crude oil spot prices gradually pick up, which in January $2009 \sim$ July 2011, crude oil prices grew steadily, but still did not break the peak of crude oil prices in 2008. July 2011 August 2014, the international crude oil futures prices and Chinese crude oil spot price is relatively stable, little fluctuation.

Table 1 statistical results show: the number of processing, the sample during the international crude oil futures prices and Chinese crude oil spot price standard deviation of 0.2546 and 0.3137 , respectively, that Chinese crude oil spot price volatility greater; international crude oil futures prices and Chinese crude oil spot The price skewness is -0.6806 and -0.6588 , respectively, showing significant left partiality; kurtosis were 2.9118 and 2.5744, respectively, less than 3; JB statistics show that the two price series are different from the normal distribution.

Table 1 International crude oil futures and Chinese spot price logarithmic basic statistics

\begin{tabular}{ccccccccc}
\hline & Mean & Max & Min & SD & Skewness & Kurtosis & JB statistic & $\begin{array}{c}\text { Number of } \\
\text { samples }\end{array}$ \\
\hline $\ln$ & 4.4428 & 4.9814 & 3.5830 & 0.2546 & -0.6806 & 2.9118 & $171.8171^{* * * *}$ & 2216 \\
$\ln$ c & 4.4081 & 4.9116 & 3.4645 & 0.3137 & -0.6588 & 2.5744 & $176.9978^{* * *}$ & 2216 \\
\hline
\end{tabular}

\section{Empirical Test}

The Basic Characteristics of Data Testing. 1. Unit root test. Table 2 shows the results of the unit root test for the logarithmic level and the first order differential sequence of the two variables. Considering that the crude oil market is susceptible to multiple external factors in the development process, in order to make the test results more robust, we also consider the unit root DF-GLS test with outliers and structural mutations (Liu et al., 2013). The results of robustness test show that the selection of non-intercept term and trend item, the international crude oil futures price and the logarithmic level of crude oil spot price are not smooth. Considering the intercept term and the non-trend item, the first order difference Sequences are smooth time series.

Table 2 International crude oil futures and Chinese crude oil spot price and first-order differential sequence of smoothness test

\begin{tabular}{|c|c|c|c|c|}
\hline & $\begin{array}{l}\text { ADF } \\
\text { value }\end{array}$ & PP statistics & DF-GLS Test & Conclusion \\
\hline $\ln f p$ & -2.1922 & -2.1934 & -2.1586 & Non-stationary \\
\hline$\Delta \ln f p$ & $-50.9040^{* * *}$ & $-50.9949^{* * *}$ & $-5.3663^{* * *}$ & smooth \\
\hline $\ln c p$ & -1.8186 & -1.9964 & -1.8460 & Non-stationary \\
\hline$\Delta \ln c p$ & $-51.2456^{* * *}$ & $-51.0681^{* * *}$ & $-4.1635^{* * *}$ & smooth \\
\hline
\end{tabular}

Granger causality test. If the variable is introduced into the equation of other variables, the degree of interpretation of the equation is improved, and the Granger causality relationship between the variables can be determine. Table 3 gives the Granger causality test results for the two market price fluctuations under the optimal lag condition under the criteria. The results show that under the $10 \%$ significance level, the international crude oil futures price and the spot price of crude oil in China are Granger causality. 
Table 3 Granger causality test between international crude oil futures prices and spot prices of crude oil in China

\begin{tabular}{lccccc}
\hline Non-zero hypothesis & $\begin{array}{c}\text { The } \\
\text { number } \\
\text { observations }\end{array}$ & F statistic & Probability & Conclusion \\
\hline$\Delta f$ is not the Granger reasons of $\Delta c$ & 2213 & 1560.2700 & 0.0000 & Refuse \\
$\Delta f \quad$ is not the Granger reasons of $\Delta c$ & 2213 & 2.5466 & 0.0786 & Refuse \\
\hline
\end{tabular}

Cointegration Test. The existence of cointegration equation. Before we perform the Johansen covariance test and the vector error correction model test, we should first determine the lag order of the model. This lag order is determined by several criteria: First, we must satisfy the mathematical stability, that is, The third, must be set by the model error test, such as the normality, autocorrelation, ARCH effect, the effect of the test, which requires that all units of the root film should count all fall in the unit circle; second, must meet the LR test standards; And heteroskedastic effects. According to the four information codes of AIC, SBIC, HQIC and FPE, we obtain the Johansen cointegration test and the optimal lag order of VEC model. Table 4 The maximum eigenvalue test and trace statistical tests show that there is at least one covariant equation between the two variables, ie, there is a cointegration relationship, and a VEC model can be established.

Table 4 International crude oil futures prices and Chinese crude oil spot price between the co-integration test

\begin{tabular}{llrrrr}
\hline $\begin{array}{c}\text { Covariant equation } \\
\text { number hypothesis }\end{array}$ & Eigenvalues & $\begin{array}{c}\text { Trace } \\
\text { statistics }\end{array}$ & $\begin{array}{c}5 \% \\
\text { critical } \\
\text { value }\end{array}$ & $\begin{array}{c}\text { Maximum } \\
\text { eigenvalue statistic }\end{array}$ & $\begin{array}{c}5 \% \\
\text { critical } \\
\text { value }\end{array}$ \\
\hline $\begin{array}{c}\text { There is nc } \\
\text { cointegration equation } \\
\begin{array}{c}\text { There is a cointegration } \\
\text { equation }\end{array}\end{array}$ & 0.0069 & 18.0824 & 15.4947 & 15.3200 & 14.2646 \\
\hline
\end{tabular}

VEC cointegration analysis. Because of the above theoretical analysis, there is at least one cointegration relationship between the sequences, so we can use the VEC model to analyze the causal relationship between the international crude oil futures price and the spot price of crude oil in China.

To this end, we get the following covariance equation:

$$
\begin{gathered}
c_{t-1}=-1.0928 f_{t-1}+1.3354 \\
(-20.6625)
\end{gathered}
$$

The covariance equation (6) shows that the covariance coefficient is $(1,-1.0928)$, close to the standard level of $(1,-1)$, indicating that the international crude oil futures market has a high pricing efficiency for Chinese crude oil spot market.

(3) The empirical results of the VEC-BEKK-GARCH $(1,1)$ model 
Table 5 International crude oil futures prices and Chinese crude oil spot price VEC-BEKK-GARCH $(1,1)$ model parameter estimation results

\begin{tabular}{|c|c|c|}
\hline parameter & $\begin{array}{l}\text { International crude oil } \\
\text { futures prices }(i=1)\end{array}$ & $\begin{array}{l}\text { Chinese crude oil spot } \\
\text { prices }(i=2)\end{array}$ \\
\hline \multicolumn{3}{|c|}{ Conditional mean equation } \\
\hline $\operatorname{ar}(1)_{1 i}$ & $0.9026^{* * *}(32.4542)$ & $0.7850^{* * *}(9.7606)$ \\
\hline $\operatorname{ar}(2)_{1 i}$ & $0.0997^{* * *}(50.7952)$ & $-0.4686^{* *}(2.1217)$ \\
\hline $\operatorname{ar}(3)_{1 i}$ & $-0.0185(1.2248)$ & $-0.3054^{* * *}(-5.0626)$ \\
\hline $\operatorname{ar}(1)_{2 i}$ & $0.0262^{* * *}(12.8043)$ & $0.5947^{* * *}(50.1339)$ \\
\hline $\operatorname{ar}(2)_{2 i}$ & $-0.0478(1.3544)$ & $0.3523^{* * *}(10.4568)$ \\
\hline $\operatorname{ar}(3)_{2 i}$ & $0.0307(1.5642)$ & $0.0428^{* * *}(6.5716)$ \\
\hline Constant term & $0.0325^{* * *}(4.1917)$ & $-0.0033(-0.5901)$ \\
\hline \multicolumn{3}{|c|}{ Conditional variance - Covariance equation: } \\
\hline$c_{1 i}$ & $0.0081^{* * *}(3.0178)$ & \\
\hline$c_{2 i}$ & $0.0014(0.9981)$ & $-0.0045^{* * *}(-6.9639)$ \\
\hline$a_{1 i}$ & $0.2249^{* * *}(10.3838)$ & $0.0012^{* * *}(6.5295)$ \\
\hline$a_{2 i}$ & $0.0026(1.4363)$ & $0.2259^{* * *}(18.0758)$ \\
\hline$b_{1 i}$ & $0.8659^{* * *}(13.0133)$ & $0.0003^{* * *}(13.8378)$ \\
\hline$b_{2 i}$ & $0.0058(0.1763)$ & $0.8665^{* * *}(7.8625)$ \\
\hline \multicolumn{3}{|c|}{ Model normalized residuals ARCH effect test $\left(\mathrm{H}_{0}\right.$ : no ARCH effects ): } \\
\hline F-test (6) & $4.7269(0.5793)$ & $7.6244(0.8138)$ \\
\hline F-test (12) & $11.6363(0.1706)$ & 23.9561(0.1206) \\
\hline $\begin{array}{l}\text { Logarithmic likelihood } \\
\text { function: }\end{array}$ & 12661.3234 & \\
\hline $\begin{array}{l}\text { Number of valid } \\
\text { samples: }\end{array}$ & 2213 & \\
\hline
\end{tabular}

The results of the two-variable VEC-BEKK-GARCH $(1,1)$ model show that the degree of inter-market price fluctuation can be expressed by the significance of the coefficients in the conditional mean equation. The results show that only the coefficient is significant at the 5\% significance level, indicating that the first-order crude oil spot price has a significant effect on the volatility of crude oil futures. At the $5 \%$ significance level, the coefficient, significant, indicates that the international crude oil futures lag behind the first, second and third order price fluctuations significantly affect Chinese crude oil spot price volatility.

In the estimation of the variance of the conditional variance, the coefficient and the estimated value are significant at the $1 \%$ significance level, which indicates that the fluctuation of the international crude oil futures price and the fluctuation of the spot price of crude oil in China is affected by its own pre-fluctuation. This result proves once again the mean value coefficient is estimated to be robust. At 1\% significance level, the coefficients and estimates are significant, indicating that the international crude oil futures prices and Chinese crude oil spot price fluctuations show the persistence of fluctuations and the impact of external factors significantly.

Coefficient, which is significant at $1 \%$ level, indicating that the impact of the conditional variance impact on the current price fluctuation and fluctuation from the international crude oil futures market has a significant effect on the current fluctuation of the spot price of crude oil in China. The coefficient estimate is at the significance level of $10 \%$ Not significant, that is, Chinese crude oil spot price on a period of volatility and volatility of the conditions of the impact of the impact of international crude oil futures prices have no significant impact. The above results show that the international crude oil futures price fluctuations on Chinese crude oil spot price fluctuations have a significant impact, and vice versa are not established. 
In order to test the validity of the VEC-BEKK-GARCH $(1,1)$ model, we test the normalized residuals of the model. The results show that there are no ARCH effects in the 6th order and 12th order and the VEC-BEKK-GARCH $(1,1)$ model can fit the volatility spillover effect between international crude oil futures price volatility and Chinese crude oil spot price.

\section{Conclusions and Policy Recommendations}

This paper chooses the international data of international crude oil futures (USD / barrel) and Chinese crude oil spot price (USD / barrel) from January 4, 2006 to August 20, 2014, using VEC-BEKK-GARCH $(1,1$ ) Model to examine whether the international crude oil futures prices affect the volatility of Chinese crude oil spot prices. (1) At the level of $10 \%$, the international crude oil futures price and the spot price of crude oil in China are Granger causality. (2) There is a long-term cointegration relationship between the international crude oil futures price and the spot price of crude oil in China (1, -1.0928), and has a high pricing efficiency. (3) At the $10 \%$ significance level, there is a significant one-way spillover effect of the international crude oil futures price on Chinese crude oil spot price fluctuation, But on the contrary does not hold.

The empirical results show that the international crude oil futures price is an important driving force for the fluctuation of the spot price of crude oil in China, and has played a positive role in stabilizing the spot price of crude oil in China. Overall, the international crude oil futures market has a high pricing efficiency and stabilizing effect on Chinese crude oil spot market. To this end, the policy recommendations in this paper are as follows: (1) Gradually establish and improve the crude oil futures market and introduce crude oil futures in line with Chinese national conditions Contract, in the country to play to play the role of crude oil futures market price guidance and risk aversion effect, to avoid the risk of international crude oil fluctuations on Chinese economic impact. (2) Do the risk of investor advocacy and risk popularization work. Crude oil futures market, high leverage and high risk, high yield may cause excessive speculation in the crude oil futures market. Therefore, in the establishment of crude oil futures market at the same time, the need to penetrate the basic knowledge of crude oil futures, strengthen the futures market risk, strengthen risk education, and guide investors to a reasonable degree of investment. (3) Diversified crude oil futures contracts are an effective way to improve the risk of crude oil market trading and diversify the risk of crude oil market trading. It is an important policy choice for the government in the coming years.

\section{Acknowledgements}

Fund Project: This paper is the National Natural Science Fund Youth Fund Project "financial factors on the corn price fluctuations in the transmission mechanism and forecasting effect: based on the perspective of grain finance" (item number: 71603153); Shaanxi Provincial Social Science Fund key project "supply side reform background Shaanxi Province, the whole industry chain value of the integration of value and value-added innovation model "(No. 2016D003); Shaanxi Normal University, the central university basic research business funds special project" gasoline prices on crude oil price fluctuations in short-term and long-term asymmetric response research "(project Number: 15SZYB18), and this article is funded by the Anhui University Rural Reform and Economic and Social Development Institute.

\section{References}

[1] Alquist R and Kilian L. What do we learn from the price of crude oil futures? Journal of Applied Econometrics, 2010, 25: 539-573.

[2] Baumeister C and Kilian L. Real-time forecasts of the real price of oil. Journal of Business and Economic Statistics, 2012, 30: 326-336.

[3] Baumeister C and Peersman G. The Role of Time-varying Price Elasticities in Accounting for Volatility Changes in the Crude Oil Market. Journal of Applied Econometrics, 2013, 28: 1087-1109. 
[4] Cox, C. C. Futures Trading and Market Information. The Journal of Political Economy, 1976, 84(6): 1215-1237.

[5] Dvir E and Rogoff K. Three epochs of oil. Mimeo, Department of Economics, Harvard University, 2010.

[6] Foster A J. Price discovery in oil markets: a time varying analysis of the 1990-91 Gulf conflict. Energy Economics, 1996,18: 231-246.

[7] Hamilton J D. Causes and consequences of the oil shock of 2007-08. Brookings Papers on Economic Activity, 2009a: 215-261. 